\title{
Vulnerable long-term psychiatric in- patients need screening for physical- health problems: An audit of regular hospital statistics and clinical files
}

\author{
C Krüger \\ Department of Psychiatry, University of Pretoria and Weskoppies Hospital, Pretoria, South Africa
}

\begin{abstract}
Objective: Maintaining physical health in the presence of severe mental illness remains a challenge. The aims of this study were to identify the most pressing physical health problems of long-term psychiatric in-patients and to identify vulnerable subgroups, as part of a multi-phased programme evaluation project to improve service delivery to and quality of care of long-term patients in Weskoppies Hospital. Method: Regular nursing statistics on vital data, infections, injuries, deaths, and adverse incidents, as well as clinical file data, infection-control statistics and dietician statistics were recorded for 268 long-term in-patients at Weskoppies Hospital over six months. Adverse incidents including aggression were recorded because of their potential for injury and nursing implications. Subgroups of patients were compared using two-way tables and Fisher's Exact Tests, or Mann-Whitney-U and KruskalWallis tests. Results: The blood pressure of hypertensive patients was well controlled. Prevalent problems were epilepsy, respiratory tract infections, and injuries (accidental and from fighting or assault). Most vulnerable are older male patients (prone to respiratory tract infections and lower body weight); patients with cognitive disorders (prone to any injury, especially accidents and falls); and younger male patients (prone to aggression and resultant injury). Conclusion: Increased screening should be conducted for older underweight male patients (for chronic respiratory or infectious diseases that might cause cachexia) and of patients with cognitive disorders or who have fallen (for treatable risk factors for falling and preventative measures). More patients should be referred for special diets. Nursing interventions should be emphasised more with aggressive and irritable patients.
\end{abstract}

Key words: Hospitals; Psychiatric; South Africa; In-patients; Physical health

Received: $12-12-2010$

Accepted: 24-06-201 1

doi: http://dx.doi.org/10.4314/ajpsy.v15i3.23

\section{Introduction}

Maintaining general physical health in the presence of severe mental illness remains a daunting challenge internationally. ${ }^{1-5}$ For psychiatric in-patients, and in particular for long-term psychiatric in-patients, the challenge of maintaining physical health often relates to inadequate monitoring of their physical problems by the treating team. ${ }^{1}$ On the other hand, inadequate self-report by the patients themselves of physical symptoms - which might be a function of psychosis or cognitive impairment - might also contribute to poor physical health maintenance.

Much of the previous research on physical-health problems of long-term patients has been done in the context of long-term care in nursing homes, more so than in the context of long-term psychiatric patients. Messinger-Rapport et al. identify the following

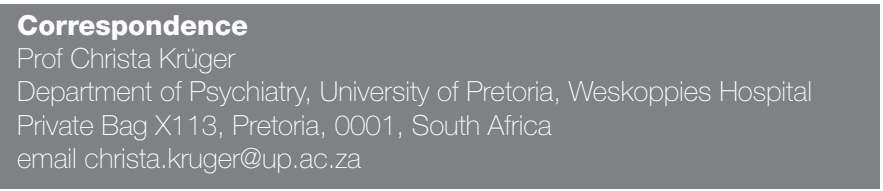

as prominent medical issues in long-term care and provide guidelines for their treatment: heart failure, vitamin D, falls, diabetes mellitus, blood pressure, anaemia, clinical nutrition, pressure ulcers, clostridium difficile infection, and insomnia. ${ }^{6}$

More specifically, Fisher et al. found the following prevalence of physical health problems in 330 long-stay psychiatric inpatients: any medical condition $84 \%$; obesity $31 \%$; serious respiratory problems $24 \%$; dental problems 23\%; hypertension 17\%; gastro-intestinal disorder 17\%; cardiovascular problems 17\%; diabetes mellitus 14\%; thyroid disease 12\%; swallowing disorder 12\%; epilepsy 12\%; and tardive dyskinesia 12\%.7 A substantial number of patients suffered from more than one medical condition. ${ }^{7}$ Similarly, Placentino et al. found medical comorbidity in $62.6 \%$ of 426 long-term psychiatric in-patients in residential facilities. ${ }^{8}$

On the whole, previous studies have focused on four main physical health issues: body weight, infections, falls, and aggression.

Body weight has been shown to change in any direction in patients with severe mental illness. Although patients on long-term 
antipsychotic treatment have mostly been demonstrated to gain weight, the opposite has also been found, indicating the need for personal follow-up of patients. ${ }^{9}$ Obesity among psychiatric inpatients has been ascribed to psychiatric settings that contribute to obesity through increased energy intake and reduced energy expenditure. ${ }^{10,11}$

Of equal concern is the problem of low body weight in longterm psychiatric in-patients. According to Salokangas et al., a low body mass index is an indicator of poor functioning in male longterm patients with schizophrenia. ${ }^{12}$ Also, patients with dementia-related disorders are prone to weight loss and malnutrition, and this may be partly related to requiring help with eating, monotonous meals, unfamiliar or unappetising food, the way that food is served, and cultural preferences. ${ }^{13}$ Malnutrition, in turn, is a predictor of mortality. ${ }^{13}$

Infections have been reported to be more prevalent in psychiatric patients than in the general population. For example, the prevalence of Hepatitis A has been found to be 33\% in psychiatric in-patients, Hepatitis B 24-32\%, Hepatitis C 19-21\%, Tuberculosis (TB) 20\%, HIV infection 10-29\% and syphilis 12-25\%, depending on the specific psychiatric population studied. ${ }^{2,14-17}$ Acute respiratory tract infections also take their toll in psychiatric patients: Patients with advanced dementia in long-term care often get pneumonia in the last six months of life (64\% prevalence) and it is often a terminal event. ${ }^{3}$ Surprisingly, when patients with dementia were compared prospectively to patients without dementia in nursing homes, those with dementia were found to have lower overall rates of infection and lower mortality rates. ${ }^{18}$

Falls are another physical health concern in long-term psychiatric patients. Patients with dementia and delirium or confusion are at a particularly high risk of falling, with institutionalised patients having a 75\% yearly prevalence of falls. ${ }^{6,19-23}$ Gait apraxia and unsteadiness often play a role in these falls. 6,19,23-27 Moreover, these patients' increased risk of falling has much to do with side-effects of psychotropic medications especially antipsychotic medications, but also antidepressants, mood stabilisers, and sedatives - or with ECT. 4,6,20,23-25

Additional factors that increase the risk of falling include female gender, atherosclerotic disease, obesity, lower limb abnormalities, hearing or vision deficits, elevated temperature, anaemia, vitamin D deficiency and postprandial hypotension. ${ }^{4,6,20,22,23}$ Most falls occur when a patient tries to stand up from a sitting position (orthostasis), tries to get out of bed, or tries to walk to the bathroom at night.6,22 In a study of 825 patients admitted for rehabilitation following acute medical illness or a surgical procedure, a previous history of falls has been demonstrated to be the most important predictor of further falls. ${ }^{23}$

Aggressive and other problematic behaviours are reported to be common among long-stay psychiatric in-patients. ${ }^{7}$ For example, $79 \%$ of the population of a long-stay in-patient psychiatric study of 330 patients had committed physical assault in the past (15\% in the previous 30 days); $63 \%$ had had violent episodes in the past (14\% in the previous 30 days); and $74 \%$ were considered 'long-term-dangerous' to themselves or others (28\% in the previous 30 days). ${ }^{7}$ Only $21 \%$ of the patients had had no problematic behaviours in the past. ${ }^{7}$ More specifically, research on gender-related risk of aggressive behaviour has yielded contradictory findings: The balance of evidence suggests that male psychiatric in-patients tend to have more aggressive behaviour, especially a higher frequency and intensity of verbal aggressive behaviour. ${ }^{28-30}$
Aggressive behaviour has also been found to be associated with involuntary admission and closed wards, or the locking of ward doors - in acute psychiatric in-patients. ${ }^{31,32}$ One interpretation is that the imposition of restrictions on patients exacerbates the problem of violence but, on the other hand, patients end up in closed wards because of their aggression. ${ }^{31,32}$ Furthermore, new psychiatric in-patients with aggressive behaviour are hospitalised for longer and have an earlier onset of illness than their non-aggressive counterparts. ${ }^{33}$ With regard to substance use, although alcohol use is reported to be associated with high levels of aggression, cannabis use is not. ${ }^{31}$ Unfortunately, the latter reference did not record data on, for example, Methamphetamine use specifically.

The aims of this study were to identify the most pressing physical-health problems faced by long-term in-patients at the local specialist psychiatric hospital, and to identify specific vulnerable subgroups. It was hoped that the findings would aid the clinical management of long-term in-patients and inform institutional decisions about the services offered at Weskoppies Hospital.

\section{Method \\ Setting}

Weskoppies Hospital in Pretoria in Northern Gauteng is a specialist psychiatric hospital that renders general adult psychiatric services to a large geographical catchment area, and also offers child services and forensic psychiatric services. Both in-patient and out-patient services are offered. In addition to the acute in-patient services, there is a decreasing number of longterm in-patients who are either undergoing extended psychiatric rehabilitation or their problems are of such a nature that previous attempts at community placement have failed. At the time of this study the hospital had 1067 beds.

\section{Design}

The study was a quantitative, descriptive audit combining clinical file data as well as regular nursing and other statistics relating to the physical health of the long-term in-patients in Weskoppies Hospital. This study formed a part of a larger multi-phased programme evaluation project to improve the clinical service delivery to and quality of care of the long-term patients in Weskoppies Hospital.

\section{Subjects}

The study subjects included all long-term psychiatric in-patients in Weskoppies Hospital between 1 April and 30 September 2007 Data was collected from ten wards: four open male wards, one semi-closed male ward, one closed male ward, three open female wards, and one closed female ward.

\section{Outcome measures}

Regular nursing statistics on vital data, infections, injuries, deaths, and adverse incidents were recorded for all long-term in-patients at Weskoppies Hospital over the six-month study period. Adverse incidents - including verbal or physical aggression, oppositionality or non-compliance with hospital rules, harassing fellow-patients, and cannabis or other substance abuse - were recorded because of their potential to result in injury or other physical-health problems, as well as their implications for psychiatric nursing.

In addition, clinical file data was recorded on general 
demographic information, current primary DSM-IV diagnoses, general medical conditions diagnosed previously or on routine or emergency physical examinations during the study period, special investigations requested, referrals to other medical/paramedical specialties and acute sedation prescribed. Regular infectioncontrol statistics and dietician statistics were also recorded.

\section{Data management and statistical analysis}

The data on all physical health problems was transferred onto study-specific data sheets approved by a statistician from the Department of Statistics, University of Pretoria. Individual patients' physical-health data - recorded from a number of different sources - was integrated with their demographic and clinical data. Multiple incidents were consolidated for each patient - e.g. separately recorded instances of injury due to falls were summated per patient. Patient means were calculated of vital data taken at regular intervals - e.g. monthly body weight and blood pressure. Daily infection statistics were converted to mean monthly statistics.

Where the data frequencies allowed, subgroups of patients were compared with respect to the variables of interest using twoway tables and Chi-Square or Fischer's Exact tests, as well as Mann-Whitney U or Kruskal-Wallis tests. Patients with missing data were excluded from analyses. The analyses were conducted by the Department of Statistics, University of Pretoria.

\section{Ethics}

This study received ethics approval from the Research Ethics Committee of the Faculty of Health Sciences, University of Pretoria. A waiver of written informed consent was granted for this study, which was exclusively records-based. Written consent to access clinical and hospital records was obtained from the Chief Executive Officer of Weskoppies Hospital. Patient confidentiality was ensured by using unique subject numbers and codes on study-specific documentation.

\section{Results}

Table I describes the demographic and clinical characteristics of the study population. Almost two-thirds of the study population were older than 45 and almost two-thirds were male. Nearly two-thirds of the study population suffered from a psychotic disorder, including schizophrenia, schizoaffective disorder, delusional disorder, substanceinduced psychotic disorder and psychotic disorder due to a general medical condition.

The mean body weight of the older patient group was significantly less than that of the younger patient group. $(p<0.001)$ (Figure 1). Although the mean blood pressure of the patients with a diagnosis of hypertension (124/79mmHg)

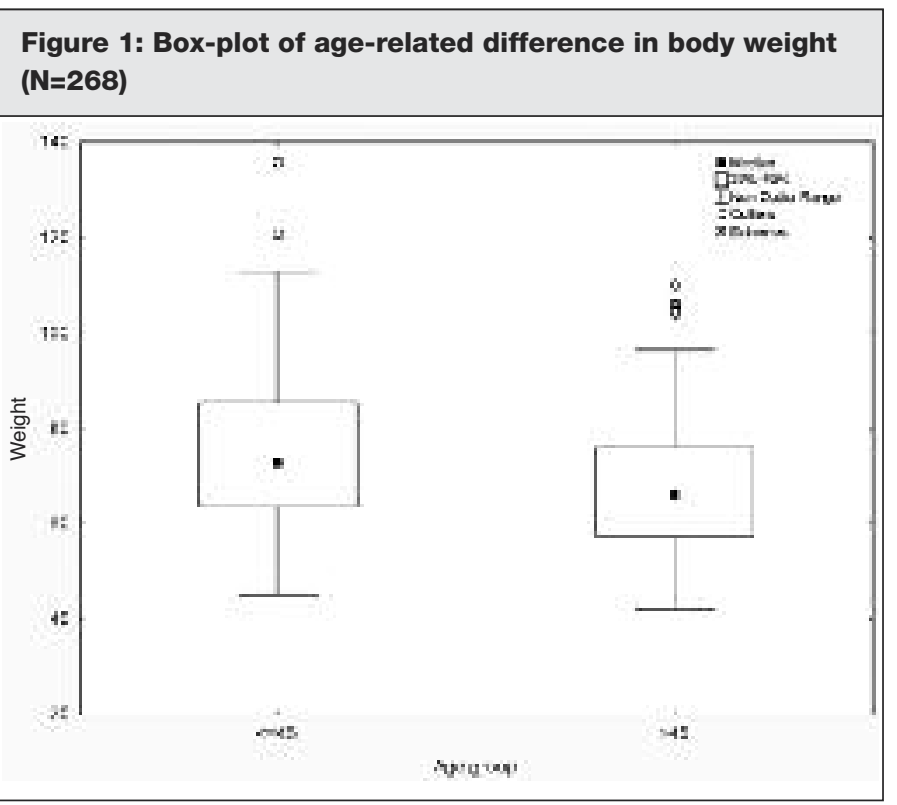

Table I: Demographic and clinical characteristics of study population

\begin{tabular}{|c|c|c|c|c|c|}
\hline & & $N$ & $\%$ & Mean & Std dev \\
\hline Age (years) & $\begin{array}{l}\text { All } \\
>45 \text { years } \\
\leq 45 \text { years }\end{array}$ & $\begin{array}{l}268 \\
169 \\
99\end{array}$ & $\begin{array}{l}100 \% \\
63 \% \\
37 \%\end{array}$ & $41.5 \mathrm{yrs}$ & 25.5 \\
\hline Gender & $\begin{array}{l}\text { Male patients } \\
\text { Female patients }\end{array}$ & $\begin{array}{l}175 \\
93\end{array}$ & $\begin{array}{l}65 \% \\
35 \%\end{array}$ & & \\
\hline Psychiatric diagnosis & $\begin{array}{l}\text { All } \\
\text { Psychotic disorders } \\
\text { Cognitive disorders } \\
\text { Mood-and-other disorders }\end{array}$ & $\begin{array}{l}264 \\
169 \\
75 \\
20\end{array}$ & $\begin{array}{l}100 \% \\
64 \% \\
28 \% \\
8 \%\end{array}$ & & \\
\hline Body weight (kg) & All & 268 & & $71 \mathrm{~kg}$ & 15.8 \\
\hline Blood pressure $(\mathrm{mmHg})$ & $\begin{array}{l}\text { All } \\
\text { Hypertensives } \\
\text { Normotensives }\end{array}$ & $\begin{array}{l}267 \\
70 \\
197\end{array}$ & $\begin{array}{l}26 \% \\
74 \%\end{array}$ & $\begin{array}{l}120 / 77 \\
124 / 79 \\
118 / 76\end{array}$ & $\begin{array}{l}13.1 / 10.5 \\
8.7 / 6.7 \\
8.3 / 5.8\end{array}$ \\
\hline Body temperature & All & 268 & & $36.2^{\circ} \mathrm{C}$ & 0.6 \\
\hline Heart rate (per min) & All & 268 & & 78 & 9.8 \\
\hline Respiratory rate (per min) & All & 268 & & 19 & 1.7 \\
\hline
\end{tabular}


was statistically significantly higher than that of the rest of the patients $(118 / 76 \mathrm{mmHg})(\mathrm{p}<0.001$ and $\mathrm{p}=0.002$ for systolic and diastolic blood pressure respectively), it was well within the normal range, and the difference was not clinically significant (Table I).

The most prevalent physical health problems are summarised in Table II. After hypertension (26\%) and epilepsy (23\%), the most prevalent health problem was respiratory tract infections (18\%). Injuries were a significant problem. Lacerations accounted for most of the injuries (15\% of all the long-term patients sustained lacerations during the study period), followed by abrasions (1 1\%).

\section{Table II: Most prevalent physical health problems}

\begin{tabular}{|c|c|c|c|}
\hline Category of health issue (and source of data) & Specific examples & Number of patients & $\%$ of 268 patients * \\
\hline $\begin{array}{l}\text { Previously diagnosed general } \\
\text { medical conditions (clinical file data) }\end{array}$ & $\begin{array}{l}\text { Hypertension } \\
\text { Epilepsy } \\
\text { Head injury } \\
\text { COPD } \\
\text { Diabetes mellitus } \\
\text { HIV/AIDS }\end{array}$ & $\begin{array}{l}70 \\
61 \\
20 \\
10 \\
9 \\
8\end{array}$ & $\begin{array}{l}26 \% \\
23 \% \\
8 \% \\
4 \% \\
3 \% \\
3 \%\end{array}$ \\
\hline $\begin{array}{l}\text { Acute general medical conditions } \\
\text { diagnosed during study period } \\
\text { (clinical file data) }\end{array}$ & $\begin{array}{l}\text { Respiratory tract infection } \\
\text { Accidental injury } \\
\text { Injury after assault }\end{array}$ & $\begin{array}{l}48 \\
35 \\
16\end{array}$ & $\begin{array}{l}18 \% \\
13 \% \\
6 \%\end{array}$ \\
\hline $\begin{array}{l}\text { Infections treated and monitored } \\
\text { (regular infection control statistics) }\end{array}$ & $\begin{array}{l}\text { Respiratory tract infection } \\
\text { HIV/AIDS } \\
\text { Skin infections } \\
\text { Wound sepsis }\end{array}$ & $\begin{array}{l}24 \\
9 \\
8 \\
5\end{array}$ & $\begin{array}{l}9 \% \\
3 \% \\
3 \% \\
2 \%\end{array}$ \\
\hline $\begin{array}{l}\text { Special investigations requested } \\
\text { (clinical file data) }\end{array}$ & $\begin{array}{l}\text { White cell count } \\
\text { Urea, creatinine, electrolytes } \\
\text { X-rays other than chest } \\
\text { Chest X-ray } \\
\text { Full blood count }\end{array}$ & $\begin{array}{l}16 \\
14 \\
11 \\
10 \\
10\end{array}$ & $\begin{array}{l}6 \% \\
5 \% \\
4 \% \\
4 \% \\
4 \%\end{array}$ \\
\hline $\begin{array}{l}\text { Routine urinalysis - positive findings } \\
\text { (regular nursing statistics) }\end{array}$ & $\begin{array}{l}\text { Protein } \\
\text { Blood } \\
\text { White blood cells }\end{array}$ & $\begin{array}{l}49 \\
16 \\
16\end{array}$ & $\begin{array}{l}18 \% \\
6 \% \\
6 \%\end{array}$ \\
\hline $\begin{array}{l}\text { Special diets prescribed (mean } \\
\text { number of patients per month) } \\
\text { (regular dietician statistics) }\end{array}$ & $\begin{array}{l}\text { Cardiac/hypertension } \\
\text { Nutrient deficiency } \\
\text { Diabetes/hypoglycaemia }\end{array}$ & $\begin{array}{l}34 \\
23 \\
21\end{array}$ & $\begin{array}{l}13 \% \\
9 \% \\
8 \%\end{array}$ \\
\hline $\begin{array}{l}\text { Referrals to other } \\
\text { medical/paramedical specialties } \\
\text { (clinical file data) }\end{array}$ & $\begin{array}{l}\text { Dentistry } \\
\text { Surgery } \\
\text { Internal Medicine } \\
\text { Dermatology }\end{array}$ & $\begin{array}{l}11 \\
6 \\
5 \\
5\end{array}$ & $\begin{array}{l}4 \% \\
2 \% \\
2 \% \\
2 \%\end{array}$ \\
\hline $\begin{array}{l}\text { Adverse incidents recorded } \\
\text { (regular nursing statistics) }\end{array}$ & $\begin{array}{l}\text { Physical aggression } \\
\text { Verbal aggression } \\
\text { Oppositionality } \\
\text { Cannabis abuse }\end{array}$ & $\begin{array}{l}33 \\
30 \\
26 \\
12\end{array}$ & $\begin{array}{l}12 \% \\
11 \% \\
10 \% \\
5 \%\end{array}$ \\
\hline $\begin{array}{l}\text { Injuries - causes of injury (regular } \\
\text { nursing statistics) }\end{array}$ & $\begin{array}{l}\text { Falls } \\
\text { Fighting } \\
\text { Self-harm } \\
\text { Assault }\end{array}$ & $\begin{array}{l}30 \\
16 \\
13 \\
11\end{array}$ & $\begin{array}{l}11 \% \\
6 \% \\
5 \% \\
4 \%\end{array}$ \\
\hline $\begin{array}{l}\text { Injuries - nature of injury (regular } \\
\text { nursing statistics) }\end{array}$ & $\begin{array}{l}\text { Lacerations } \\
\text { Abrasions } \\
\text { Head injury } \\
\text { Fracture }\end{array}$ & $\begin{array}{l}41 \\
28 \\
11 \\
7\end{array}$ & $\begin{array}{l}15 \% \\
11 \% \\
4 \% \\
3 \%\end{array}$ \\
\hline $\begin{array}{l}\text { Acute sedation prescribed (clinical } \\
\text { file data) }\end{array}$ & $\begin{array}{l}\text { Lorazepam } \\
\text { Antipsychotic medication }\end{array}$ & $\begin{array}{l}11 \\
7\end{array}$ & $\begin{array}{l}4 \% \\
3 \%\end{array}$ \\
\hline
\end{tabular}


Accidental injury (13\%) occurred more frequently than injury after fighting or assault (10\%), even though physical aggression (12\%) was a common occurrence. Falls were the single most common cause of injury ( $11 \%$ of patients). Although 26\% of patients had been diagnosed as hypertensive (Table I), only 13\% of patients were receiving special "cardiac/hypertension" diets (Table II).

The data indicated a relatively low prevalence of physical health problems and allowed for the statistical analysis of only a few of the most prevalent problems.

When analysed by age subgroups, a significantly greater proportion of older patients ( $>45$ years) suffered

\section{Figure 2: Age-group-related differences in frequency of physical health problems $(\mathrm{N}=207)$}

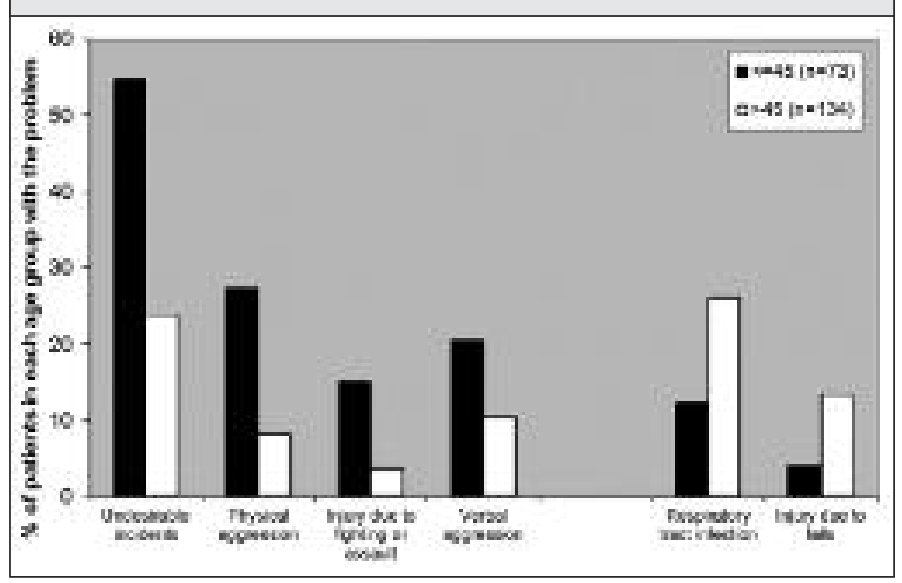

from respiratory tract infections and injury due to falls than the younger patients (Table III and Figure 2). A significantly greater proportion of younger patients $(\leq 45$ years) showed aggression and other adverse incidents, as well as injury due to fighting or assault than the older patients (Table III and Figure 2). A significantly greater proportion of male patients than female patients showed aggression and other adverse incidents, injury due to fighting or assault, as well as respiratory tract infections (Table III and Figure 3).

A significantly greater proportion of patients with cognitive disorders (dementia or mental retardation) sustained any kind of injury - particularly accidental injury, injury due to falls, abrasions and lacerations - when

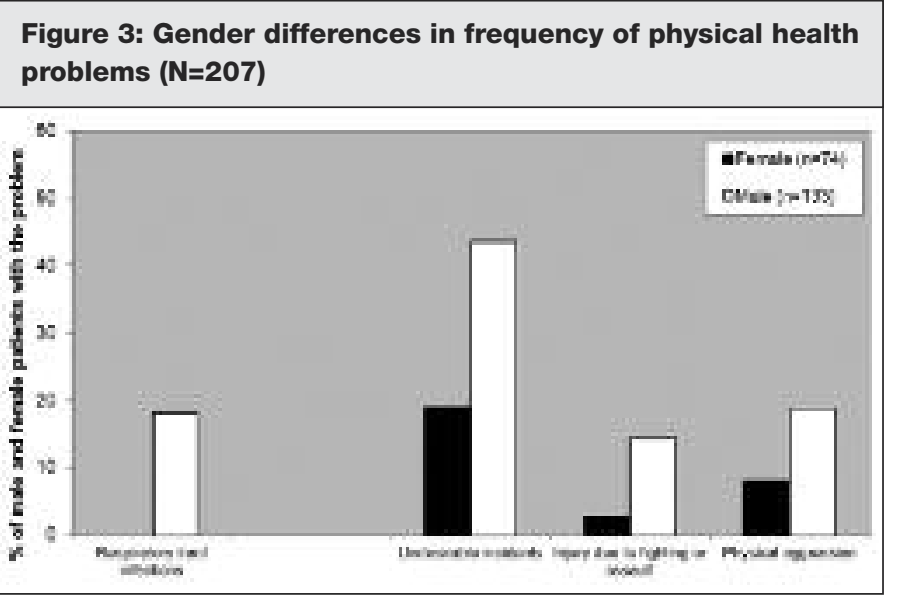

Table III: Profile of patients with physical health problems

In terms of age, younger patients ( $\leq 45$ years) demonstrated the following in comparison with older patients ( $>45$ years):

\begin{tabular}{|c|c|c|}
\hline \multirow[t]{4}{*}{ Physical problems relating to behaviour } & Adverse incidents (more) & $\mathrm{p}<0.0001^{\star *}$ \\
\hline & Physical aggression (more) & $p 0.0002^{\star \star}$ \\
\hline & Injury due to fighting or assault (more) & p $0.0035^{\star \star}$ \\
\hline & Verbal aggression (more) & p 0.0455 * \\
\hline \multirow[t]{2}{*}{ Physical problems relating to illness } & Respiratory tract infection (less) & p 0.0205 * \\
\hline & Injury due to falls (less) & p 0.0338 * \\
\hline
\end{tabular}

In terms of gender, male patients demonstrated the following in comparison with female patients:

$\begin{array}{lll}\text { Physical problems relating to illness } & \text { Respiratory tract infections (more) } & \text { p 0.0001 ** } \\ \text { Physical problems relating to behaviour } & \text { Adverse incidents (more) } & \text { Injury due to fighting or assault (more) } \\ & \text { Physical aggression (more) } 0.0082 \text { ** } \\ & \text { p 0.0389 * }\end{array}$

In terms of psychiatric diagnosis, patients with cognitive disorders demonstrated the following in comparison with patients with other diagnoses:

\begin{tabular}{|c|c|c|}
\hline \multirow[t]{6}{*}{ Injury } & Injury due to any cause (more) & p 0.0005 ** \\
\hline & Injury of any nature (more) & p $0.0005^{* *}$ \\
\hline & Accidental injury (more) & p $0.0011^{\star *}$ \\
\hline & Injury due to falls (more) & p 0.0168 * \\
\hline & Abrasions (more) & p 0.0122 * \\
\hline & Lacerations (more) & $\mathrm{p} 0.0444$ * \\
\hline \multirow[t]{2}{*}{ Infection } & Respiratory tract infections (more in cognitive, and mood-and-other disorders) & p $0.0018^{* \star}$ \\
\hline & Any infection (more in cognitive, and mood-and-other disorders) & p 0.0022 ** \\
\hline
\end{tabular}


compared to patients with other diagnoses (Table III and Figure 4). A significantly smaller proportion of patients with psychotic disorders contracted respiratory tract infections or other infections in comparison with patients with other diagnoses (Table III and Figure 4). Seven patients died during the study period. Table IV summarises their demographic and clinical data, and likely causes of death.

\begin{tabular}{|c|c|}
\hline & $N$ \\
\hline Total number of patients who died & 7 \\
\hline $\begin{array}{l}\text { Gender } \\
\text { Male } \\
\text { Female }\end{array}$ & $\begin{array}{l}3 \\
4\end{array}$ \\
\hline $\begin{array}{l}\text { Age at death ( } \text { mean }=58 \text { years) } \\
\text { Age group } 46-54 \text { years } \\
\text { Age group } 60-76 \text { years }\end{array}$ & $\begin{array}{l}4 \\
3\end{array}$ \\
\hline $\begin{array}{l}\text { Primary psychiatric diagnosis } \\
\text { Schizophrenia } \\
\text { Mental retardation }\end{array}$ & $\begin{array}{l}6 \\
1\end{array}$ \\
\hline $\begin{array}{l}\text { General medical history } \\
\text { Hypertension } \\
\text { Chronic renal failure } \\
\text { Osteo-arthritis } \\
\text { Deafness }\end{array}$ & $\begin{array}{l}4 \\
1 \\
1 \\
1\end{array}$ \\
\hline $\begin{array}{l}\text { Cause of death } \\
\text { Myocardial infarction (confirmed or suspected) } \\
\text { Pulmonary embolism (confirmed or suspected) } \\
\text { Bronchial infarction }\end{array}$ & $\begin{array}{l}5 \\
2 \\
1\end{array}$ \\
\hline
\end{tabular}

\section{Figure 4: Psychiatric-diagnosis-related differences in frequency of physical health problems ( $N=205)$}

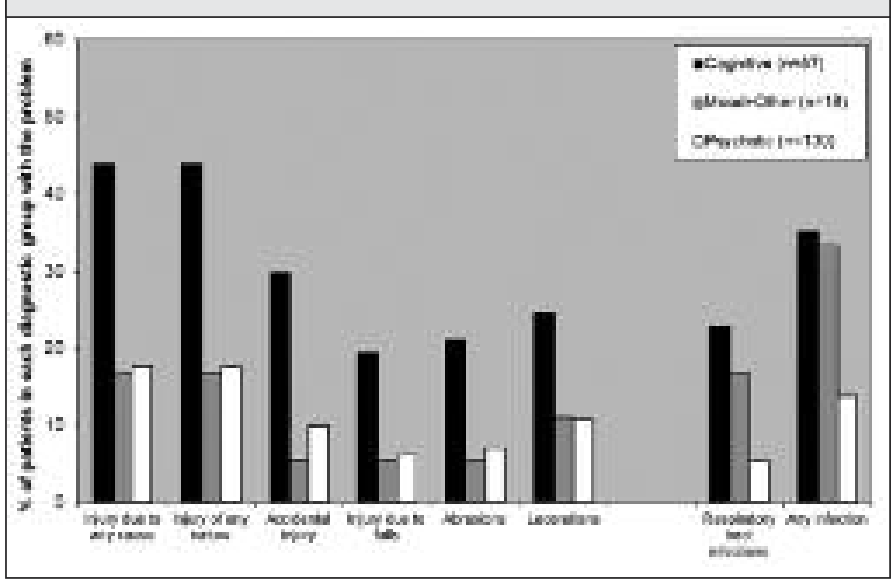

\section{Discussion}

In summary, the main findings of this study were

- The blood pressure of the hypertensive patients appeared to be well controlled;
- Other prevalent physical health problems included epilepsy, respiratory tract infections, and injuries (mostly lacerations, mostly accidental, and mostly due to falls, although fighting and assault also frequently resulted in injury);

- Older patients' (>45 years) body weight was statistically significantly lower than that of the younger patients;

- Older patients (>45 years) and male patients were statistically significantly more prone than other subgroups to respiratory tract infections;

- Younger patients ( $\leq 45$ years) and male patients were statistically significantly more prone than their counterparts to aggression and other adverse incidents, as well as to injury due to fighting or assault;

- Patients with cognitive disorders were significantly more likely than patients with other diagnoses to sustain any type of injury - especially accidental injury and injury due to falls that result in lacerations and abrasions; and

- Patients with psychotic disorders were significantly less likely than patients with other diagnoses to contract any kind of infection.

Although the blood pressure of hypertensive patients appeared to be well controlled, only $13 \%$ of the patients were receiving special "cardiac/hypertension" diets. In addition to increasing referral to the hospital dietician, nursing staff might benefit from refresher training on how to measure blood pressure appropriately, especially in older patients, as well as on the importance of orthostasis. ${ }^{6}$ The prevalence of the metabolic syndrome in these long-term patients is presently being investigated in a separate local study. It is notable that the high prevalence of hypertension among the long-term patients is reflected also among the seven patients who died during the study period (Table IV). It is possible that hypertension may have been a contributing factor in their deaths.

The low body weight of the older patients may be a cause for concern. However, it is a limitation of the study that the patients' heights were not measured, and hence their body mass indices could not be calculated to determine if they were actually underweight. Nevertheless, one wonders about possible dietary insufficiency. Only 9\% of patients were receiving special "nutrient deficiency" diets (Table II). This proportion might possibly be increased in future.

However, low body weight is not always an indication of malnutrition and the pathophysiological mechanism is not always that of starvation. ${ }^{6}$ A common alternative mechanism may be the anorexia/cachexia syndrome that is directly related to underlying inflammatory states, such as is found in AIDS, cancer, rheumatoid arthritis, renal problems, chronic obstructive airways disease (COPD), ischaemic cardiomyopathy, and infectious diseases. ${ }^{6}$ Cachexia, unlike starvation, is resistant to hypercaloric feeding. ${ }^{6}$

Hence, the older patients with low body weight should have their body mass indices calculated, and might fruitfully undergo screening for underlying inflammatory conditions such as cancer, COPD, rheumatoid arthritis and ischaemic cardiomyopathy. ${ }^{6}$ More especially perhaps, they should undergo screening for chronic infectious diseases, including TB, HIV and syphilis. ${ }^{5,16,17}$ It should be noted, 
though, that some of the traditional methods of screening have been reported as inadequate. 5,16,17

The management of the respiratory health of the older and male patients is also a cause for concern. Of the 18\% of patients who had confirmed respiratory tract infections, only half of them were being monitored by the infection-control department (Table II). Although the higher rate of respiratory tract infections among older and male patients might possibly reflect mostly acute viral upper respiratory tract infections, the possibility that these patients might have undiagnosed chronic respiratory problems (that might contribute to low body weight through cachexia) is worrying. In this study the prevalence of previously diagnosed COPD was only 4\% (Table II) and only two patients were being treated for TB. Ideally, the older and male patients should undergo thorough screening for $\mathrm{COPD}$ and TB.

The surprising finding that the patients with psychotic disorders were less likely than patients with other diagnoses to suffer from any kind of infection might not be reliable and might perhaps rather indicate an impaired ability to report physical-health problems to the staff. The possibility that patients with psychotic disorders might have a high prevalence of previously undiagnosed chronic respiratory problems or other chronic infectious diseases, for example, should ideally be investigated through proper screening.

The relatively high prevalence of accidental injury and falls in this study, especially among patients with cognitive disorders, calls for a renewed emphasis on preventative measures. First, at-risk patients need to be identified. In this regard, the simple mnemonic in Messinger-Rapport et al. of "Safe and Sound" may offer a cost-effective way of screening for risk factors of falling: Strength problems;

Alcohol in excess; Food-associated hypotension;

Environmental factors; $\mathbf{A}$ therosclerotic disease (syncope);

No freedom (restraints); Drugs; Sight (and hearing)

problems; Orthostasis; Unsteady balance; Nocturia;

Delirium. ${ }^{6}$ Moreover, it is important to screen for anaemia that may cause not only falls, but also myocardial infarction, fatigue, mobility impairment, functional impairment and an impaired quality of life. ${ }^{6}$ Interestingly, Olsson et al.

demonstrated in 364 residents of long-term care facilities diagnosed with dementia that a clock test of visuo-spatial ability may predict the risk of falling, and thus offer an opportunity for preventive intervention. ${ }^{27}$

Such screening - or at the least, such secondary evaluation of patients who have fallen - would inform a targeted approach to the prevention of falls. ${ }^{21,23}$ Alongside targeted interventions, multidisciplinary multiple intervention programmes have been recommended, including alert bracelets, attention to flooring and corridor lighting, additional exercises (as might be done in physiotherapy) and hip protectors. ${ }^{21,23}$ Notably, restraint does not necessarily reduce falling - cf. Weintraub \& Spurlock who studied the files of 767 patients treated in a psychogeriatric in-patient unit and found that a reduction in the use of restraints did not result in increased falling. ${ }^{26}$

Although the prevalence of physical aggression in this study is slightly lower than that reported by Fisher et al., the finding that the younger and male patients were more prone than their counterparts to aggression, other adverse incidents, and injury due to fighting or assault is well described in the literature. ${ }^{7,28}$ These patients might benefit from a renewed emphasis on nursing interventions such as engaging in strategic non-interaction with patients who are judged to be irritable and likely to be aggressive (i.e. being flexible and tolerant). ${ }^{31}$

This study's design of monitoring regular nursing statistics, as well as infection-control and dietician statistics, and integrating the various sources of data with available demographic and clinical data per patient made possible some original findings. The fact that the results of this study are mostly supportive of international studies suggests that these findings might be generalisable. It is notable that the prevalence of substance-related problems was lower in this study than in previous studies (Table II). 7,35,36 This might relate to the fact that file data on substance abuse was recorded here, instead of questionnaire data that is usually considered more reliable. ${ }^{37}$

The study had a number of limitations. Some clinical information was not recorded in sufficient detail: First, the distinction between acute and chronic respiratory tract infections was not recorded clearly on all the relevant data sheets, and neither were the distinctions between upperand lower-, or between viral- or bacterial respiratory tract infections. Hence, the assumption that most of the respiratory tract infections diagnosed during the study period were acute viral-upper-respiratory tract infections might not be justified, even though it is known that TB was excluded from those respiratory tract infections. Second, it would have been useful to have recorded the presence or absence of polydipsia. ${ }^{38}$

Moreover, patients' height was not recorded, which precluded a calculation of their body mass indices, which in turn made it impossible to determine the prevalence of patients who were either underweight or overweight. Whereas a figure for the prevalence of obesity might have helped in interpreting the finding in this study of a high prevalence of falls in patients with cognitive disorders, a prevalence figure of patients who were underweight might have helped in interpreting the older patients' body weight, which was lower than that of the younger patients.

Furthermore, the small study population and the sparseness of the data precluded an analysis of specific predictors of physical health problems, such as, for example, the potential effect of medication on patient falls in this study. Another limitation is that this was a retrospective study, which means that causality could not be determined for significant correlations. The number of patients that had to be excluded from some analyses due to missing data amounted to just over 20\% in some instances (Figures 2-4) and this may have had an impact on the validity of the results. This problem of missing data arose due to the fact that individual patients' physical-health data - recorded from various sources - had to be integrated with their demographic and clinical data, and not all patients had all kinds of data available.

In managing the above-identified physical-health problems, three subgroups of long-term psychiatric in-patients might benefit either from specific screening activities or from 
nursing or other paramedical interventions:

- The older male patients who are prone to respiratory tract infections and lower body weight;

- The patients with cognitive disorders (dementia or mental retardation) who are vulnerable to any kind of infection or injury, especially accidental injury and falls; and

- The younger male patients who are prone to aggression and resultant injury.

\section{Recommendations}

The following interventions are recommended:

- Continue the current practice of routine vaccination against influenza of all older and long-term psychiatric in-patients to help alleviate their burden of respiratory tract infection;

- Screen the older male long-term patients, as well as those with enduring psychotic disorders, who are also underweight for respiratory conditions such as COPD and TB that may cause chronic inflammatory states and cachexia;

- Screen the older male long-term patients, as well as those with enduring psychotic disorders, who are also underweight for other chronic infectious diseases, including HIV and syphilis;

- Screen all patients who have fallen and patients with cognitive disorders for the presence of treatable risk factors of falling using the mnemonic above, the clock test of visuo-spatial ability, as well as a finger-prick haemoglobin level;

- Treat and apply possible relevant prevention strategies for all patients whose screening results for the above conditions are positive;

- Refer more long-term psychiatric in-patients to dieticians, with a view to: a) prescribing more special "nutrient deficiency" diets to underweight patients for whom screening did not identify a specific chronic inflammatory condition; b) prescribing more special "cardiac/hypertension" diets to hypertensive patients; and c) prescribing additional fibre in the meals of patients with postprandial hypotension; 6

- Refer more long-term psychiatric in-patients with respiratory tract infections to the infection-control department for monitoring; and

- Arrange refresher training for nurses regarding orthostasis, the appropriate measurement of blood pressure (especially in older people), and interventions for the management of aggressive and irritable patients.

\section{Conclusion}

The most pressing physical health problems faced by longterm patients in Weskoppies Hospital are hypertension, epilepsy, respiratory tract infections and injury (mostly accidental but also from fighting and assault). The most vulnerable subgroups of patients appear to be the older male patients who are prone to respiratory tract infections and lower body weight; the patients with cognitive disorders who are vulnerable to any infection or injury, especially accidental injury and falls; and the younger male patients who are prone to aggression and resultant injury.

The clinical management of the long-term in-patients might benefit from increased and thorough screening of older and underweight male patients for chronic respiratory conditions, chronic infectious diseases and other conditions that might cause cachexia. Moreover, increased screening of patients who have fallen and patients with cognitive disorders for treatable risk factors of falling might help in putting preventative measures in place. In addition, more patients might be referred for a dietician's input to have their special dietary requirements met. Furthermore, nursing interventions might be utilised even more frequently than they are already for the management of aggressive and irritable patients. The hope is that the implementation of the above recommendations might contribute to improvements in the long-term patients' general physical health, mobility, level of functioning and quality of life.

\section{Acknowledgements}

The author is grateful to Mr F.N. van Zyl and Ms C.R. CollinsMcKinnell (research assistants in the Department of Psychiatry, University of Pretoria respectively in 2007 and 2008-2010) for their assistance with data collection and data management. The author is also grateful to Ms J.

Sommerville and Ms R. Ehlers of the Department of Statistics, University of Pretoria for their assistance with electronic data management, statistical analyses and interpretation of the data; and to Mrs M.A. Mabena, CEO of Weskoppies Hospital for enabling the research at the hospital.

\section{References}

1. Ludwick JJ, Oosthuizen PP. Screening for and monitoring of cardio-metabolic risk factors in outpatients with severe mental illness in a primary care setting. African Journal of Psychiatry 2009; 12(4):287-92

2. Rothbard AB, Blank MB, Staab JP, TenHave T, Young DS, Berry SD, et al. Previously undetected metabolic syndromes and infectious diseases among psychiatric inpatients. Psychiatric Services 2009; 60(4):534-7.

3. Chen JH, Lamberg JL, Chen YC, Kiely DK, Page JH, Person CJ, et al. Occurrence and treatment of suspected pneumonia in longterm care residents dying with advanced dementia. Journal of the American Geriatrics Society 2006; 54(2):290-5.

4. Nakagawa A, Sato T, Endo Y, Watanabe K, Kashima H, Grunebaum MF. Prospective study of falls in long-term inpatients with chronic psychotic disorders. Schizophrenia Research 2006; 88(1-3):283-5.

5. Harada $N$, Higuchi $K$, Mori T. Assessment of nosocomial transmission of tuberculosis in a psychiatric hospital using a whole blood interferon-gamma assay. Japanese Journal of Infectious Diseases 2008; 61 (5):415-8.

6. Messinger-Rapport BJ, Morley JE, Thomas DR, Gammack JK. Intensive session: New approaches to medical issues in longterm care. Journal of the American Medical Directors Association 2007; 8(7):421-33.

7. Fisher WH, Barreira PJ, Geller JL, White AW, Lincoln AK, Sudders M. Long-stay patients in state psychiatric hospitals at the end of the 20th century. Psychiatric Services 2001; 52(8):1051-6.

8. Placentino A, Rillosi L, Papa E, Foresti G, Materzanini A, Rossi G, et al. Clinical characteristics in long-term care psychiatric patients: A descriptive study. World Journal of Biological Psychiatry 2009; 10(1):58-64. 
9. Tadger S, Melamed Y. Weight gain due to long term antipsychotic treatment of persistent mental disorders. Psychiatria Danubina 2008; 20(1):37-41

10. Faulkner GE, Gorczynski PF, Cohn TA. Psychiatric illness and obesity: Recognizing the "obesogenic" nature of an inpatient psychiatric setting. Psychiatric Services 2009; 60(4):538-41.

11. Sansone RA, Wiederman MW, Sansone LA, Monteith D. Obesity and borderline personality symptomatology: Comparison of a psychiatric versus primary care sample. International Journal of Obesity \& Related Metabolic Disorders 2001; 25(2):299-300.

12. Salokangas RK, Honkonen T, Stengard E, Hietala J. Body mass index and functioning in long-term schizophrenia: Results of the DSP project. European Psychiatry: the Journal of the Association of European Psychiatrists 2007; 22(5):313-8.

13. Carrier N, West GE, Ouellet D. Cognitively impaired residents' risk of malnutrition is influenced by foodservice factors in long-term care. Journal of Nutrition for the Elderly 2006; 25(3-4):73-87.

14. Pirl WF, Greer JA, Weissgarber C, Liverant G, Safren SA. Screening for infectious diseases among patients in a state psychiatric hospital. Psychiatric Services 2005; 56(12):1614-6.

15. Lacey C, Ellen S, Devlin H, Wright E, Mijch A. Hepatitis C in psychiatry inpatients: Testing rates, prevalence and risk behaviours. Australasian Psychiatry 2007; 15(4):315-9.

16. Henning MP, Krüger C, Fletcher L. HIV sero-positivity in recently admitted and long-term psychiatric in-patients: Prevalence and diagnostic profile. African Journal of Psychiatry 2012;15(1):47-53.

17. Henning MP, Krüger C, Fletcher L. Syphilis sero-positivity in recently admitted and long-term psychiatric in-patients: Prevalence and diagnostic profile. Poster presentation. 16th Biennial National Congress of the South African Society of Psychiatrists (SASOP), East London, South Africa, 16 - 20 October 2010

18. Magaziner J, Zimmerman S, Gruber-Baldini AL, Van Doorn C, Hebel JR, German P, et al, for the Epidemiology of Dementia in Nursing Homes Research Group. Mortality and adverse health events in newly admitted nursing home residents with and without dementia. Journal of the American Geriatrics Society 2005; 53(11):1858-66.

19. Cotter VT. Restraint free care in older adults with dementia. Keio Journal of Medicine 2005; 54(2):80-4

20. De Carle AJ, Kohn R. Risk factors for falling in a psychogeriatric unit. International Journal of Geriatric Psychiatry 2001; 16(8):762-7.

21. Nair A, Parr H, Whitelock H, Hanspal RS. Prevention of falls in hospital inpatients. Journal of the Royal Society of Medicine 2005; 98(1):45

22. Tsai YF, Witte N, Radunzel M, Keller ML. Falls in a psychiatric unit Applied Nursing Research 1998; 11 (3):115-21

23. Vassallo M, Vignaraja R, Sharma JC, Briggs R, Allen SC. Predictors for falls among hospital inpatients with impaired mobility. Journal of the Royal Society of Medicine 2004; 97:266-9.
24. Detweiler MB, Murphy PF, Kim KY, Myers LC, Ashai A. Scheduled medications and falls in dementia patients utilizing a wander garden. American Journal of Alzheimer's Disease \& Other Dementias 2009; 24(4):322-32

25. Martin H, Slyk MP, Deymann S, Cornacchione MJ. Safety profile assessment of risperidone and olanzapine in long-term care patients with dementia. Journal of the American Medical Directors Association 2003; 4(4):183-8. [Erratum appears in J Am Med Dir Assoc. 2003;4(5):290].

26. Weintraub D, Spurlock M. Change in the rate of restraint use and falls on a psychogeriatric inpatient unit: Impact of the health care financing administration's new restraint and seclusion standards for hospitals. Journal of Geriatric Psychiatry \& Neurology 2002; 15(2):91-4.

27. Olsson RH Jr, Wambold S, Brock B, Waugh D, Sprague H. Visual spatial abilities and fall risk: An assessment tool for individuals with dementia. Journal of Gerontological Nursing 2005; 31 (9):45-51.

28. Krüger C, Rosema D. Risk factors for violence among long-term psychiatric in-patients: A comparison between violent and nonviolent patients. African Journal of Psychiatry 2010; 13(5):366-375

29. Grube M. Gender differences in aggressive behavior at admission to a psychiatric hospital. Aggressive Behavior 2007; 33(2):97-103.

30. Uppal G, McMurran M. Recorded incidents in a high-secure hospital: A descriptive analysis. Criminal Behaviour \& Mental Health 2009; $19(4): 265-76$

31. Bowers L. Allan T, Simpson A, Jones J, Van Der Merwe M, Jeffery D. Identifying key factors associated with aggression on acute inpatient psychiatric wards. Issues in Mental Health Nursing 2009; 30(4):260-71

32. Van der Merwe M, Bowers L, Jones J, Simpson A, Haglund K. Locked doors in acute inpatient psychiatry: A literature review. Journal of Psychiatric and Mental Health Nursing 2009; 16(3):293-9

33. Chang JC, Lee CS. Risk factors for aggressive behavior among psychiatric inpatients. Psychiatric Services 2004; 55(11):1305-7.

34. South African Mental Health Care Act, No. 17 of 2002. Government Gazette 6 November 2002; vol. 449, no. G24024

35. Katz G, Durst R, Shufman E, Bar-Hamburger R, Grunhaus L. Substance abuse in hospitalized psychiatric patients. Israel Medical Association Journal: Imaj 2008; 10(10):672-5.

36. Pacula RL, Ringel J, Dobkin C, Truong K. The incremental inpatient costs associated with marijuana comorbidity. Drug \& Alcohol Dependence 2008; 92(1-3):248-57

37. Shourie S, Conigrave KM, Proude EM, Haber PS. Detection of and intervention for excessive alcohol and tobacco use among adult hospital in-patients. Drug and Alcohol Review 2007; 26(2):127-33.

38. De Leon J. Polydipsia: A study in a long-term psychiatric unit European Archives of Psychiatry \& Clinical Neuroscience 2003; 253(1):37-9 